(1997年3月24日受付・1997年6月 4 日受理)

\title{
アクリロニトリルの溶融均一相重合
}

\author{
日本エクスラン工業桻) 塩田博孝 \\ 金沢大学教育学部 松平光里
}

\section{Polymerization of acrylonitrile in homogeneous melt phase.}

\author{
Hirotaka Shiota ${ }^{* 1}$, Mitsuo Matsudaira ${ }^{* 2}$ \\ *1 Japan EXLAN Company, 3-3-1, Kanaoka-higashimachi, Okayama-City,Okayama, 704 Japan \\ ${ }^{* 2}$ Faculty of Education, Kanazawa University, Kanazawa-City, Ishikawa, 920-11 Japan
}

\begin{abstract}
Polymerization behavior of acrylonitrile (AN) and methylacrylate (MA) was investigated in homogeneous melt phase. It was found that homogeneous melted mixture of polyacrylonitrile, acrylonitrile, and water could be prepared through the polymerization of AN and MA in water (monomer/water $=80 / 20$ ) at conversion over $80 \%$. Reactivity ratio of the polymerization showed that higher alternating tendency and closer composition with monomer mixture than those in bulk and dispersion polymerization.
\end{abstract}

(Received 24 March, 1997 ; Accepted 4 June, 1997)

\section{1. 緒言}

アクリル織維は一般に溶剤中での溶液重合あるいは水 柔㬎濁重合で作成しなポリアクリロニトリル系重合体(PAN) を溶㖃に溶解して紡杀原液を作成し，湿式，乾式あるい は乾湿式紡系法で生産されている。溶剂在用いた紡系法 は溶郕の除去/回収/精製工程を必要とするため,ポリ工 ステル，ナイロンなどに用いられている溶融紡系法に比 へて設備費，必要エネルギーの両面で不利とされている。 PANへの溶融紡系法の適用に関して, 前報(1)において $\mathrm{PAN} / \mathrm{AN} /$ 水の 3 成分系の溶融挙動を娭討し, 従来から 知られている水の見かけの融点低下效果に比べて水/AN 混合物を添加した場合には著しく見かけの融点が低下寸 ることを報告した。また，溶融体に相分品倠を生じない成 分組成は, $\mathrm{PAN}$ 中のCN基と $\mathrm{H}_{2} \mathrm{O}$ O モル比が 1 対 1 , $\mathrm{H}_{2} \mathrm{O}$ とANのモル比が2対 1 の時に理想的に得られること, すなわち, Fig.1の点Cは水 $/ \mathrm{AN}=18 / 82 の$ 組成であり，重 合が進むにつれて重合系内の組成は線CD上をDの方向に 進み，組成が点Oに達したとき $\mathrm{CN} / \mathrm{H}_{2} \mathrm{O} / \mathrm{AN}=2 / 2 / 1$ とな り均一溶融体が得られることを示しな。本報ではまず水 モノマーの溶解度 (相溶性)に对する温度による影響を調 ヘ，均一相となる温度範囲を決定しそのの条件下での重
合がどのような挙動寺すかを検討した。また，重合温 度が通常の水系重台などに对し高温上なるため，ポリマ 一の着色が想されることから着色防止剂の効果につい ても調べた。

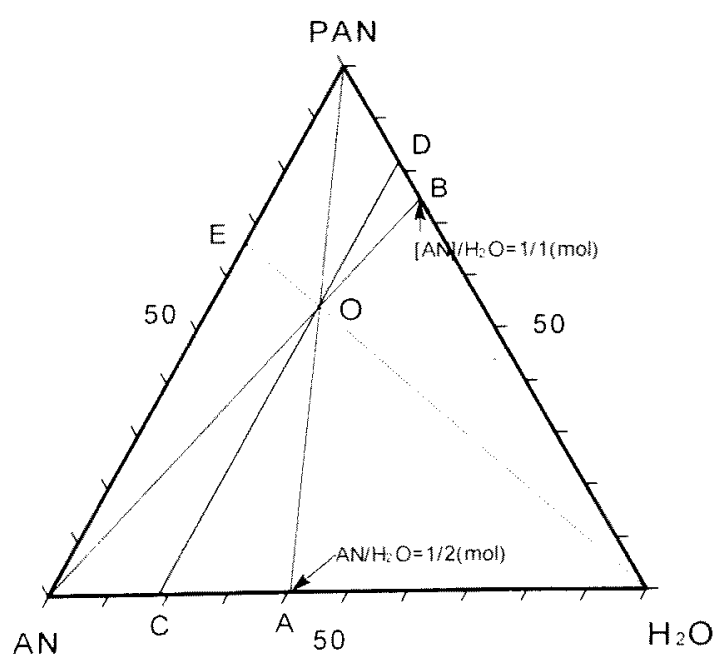

Fig. 1 Phase diagram of PAN/AN/ $\mathrm{H}_{2} \mathrm{O}$. 


\section{2. 実 験}

\section{1 試料}

実験に用いたモノマーは住友化学工業獭製アクリロ二 トリル (AN)，日東化学(懒製メチルアクリレート(MA), 日本合成釉製酢酸ビ二ル (VAc)，および林純薬(侏試薬 1 級メチルメタアクリレート (MMA)をそのまま使用した。

また，各種重合開始剤は市販の試薬 1 級あるいは工業 用グレードをそのまま使用した。

\section{2 水/モノマ一相溶性}

ガラス哯き空を備えた容量 $13 \mathrm{ml}$ の耐圧セルに水/モノマ 一混合物を充填し, 油浴中で昇温速度 $1^{\circ} \mathrm{C} /$ 分で加熱しな がら内容物を観察して均一相になった温度を相溶温度と した.

\section{2 重合}

容量約 $10 \mathrm{ml}$ のガラス封管に水/モノマー/重合開始郕を 仕込み，あらかじめ温度を設定した油浴に浸漬し，封管 を摇動させながら反応させ、所定時間経過後, 封管を油 浴から取り出し，水水中に投入して椧却，反応を停止さ せた。冷却後封管を開封して内容物を取り出し重合体量 を測定した。

\section{4 分析}

重合体のAN成分は柳本製作所製CHNコーダーを用い, アンチピリン (C:70.19\%，H：6.43\%：N14.88\%)を標 隼物質として窒素含量孛求め, その值から重合体中のAN 組成算出した。

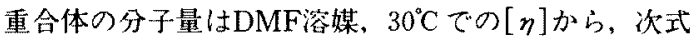
(3)老用いて求めた。

$$
[\eta]=3.35 \times 10^{4} \mathrm{Mw}^{0.72}
$$

また, 重合体の着色度は重合体 $0.4 \mathrm{~g} 20 \mathrm{ml}$ のDMFに溶 解し, 波長 $420 \mathrm{~nm}$ の吸光度からAPHA指数を算出して評 価しな。

\section{3. 結果およU゙考察}

\section{1 水/モノマーの相溶性}

Fig.2にAN/水系およびAN/MA/水系の相图を示した。 温度の上昇と共に水に対するANの溶解度およU゙ANに対 する水の溶解度は共に上昇し $145^{\circ} \mathrm{C}$ 以上では水とANはあ らゆる組成比で相溶し，均一相となることが分かった。

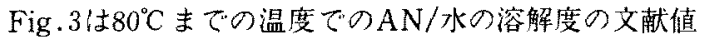
(2)であるが, 測定值とよく一致しておりFig.2の妥当性 を支持している。

モノマーとしてAN/MA混合物 $(90 / 10$ 重舅\%)を用いた 場合には，AN/水の2 成分系に比べて相溶温度はやや高 めとなったが、大きく変わらながった， $25^{\circ} \mathrm{C} に お け る \mathrm{MA}$ の水に対する溶解度は $5.2 \%$, MAに対寸る水の溶解度は

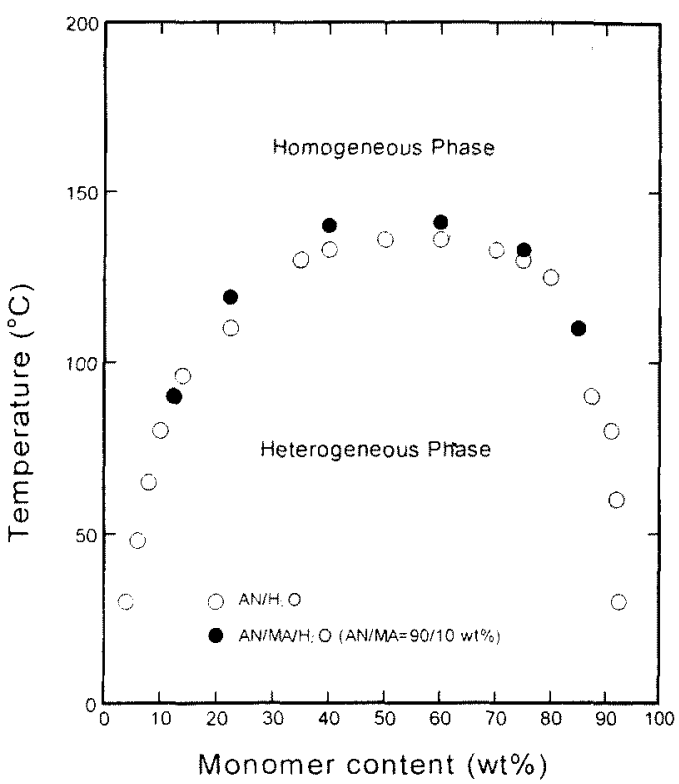

Fig. 2 Phase diagram of monomer/water.

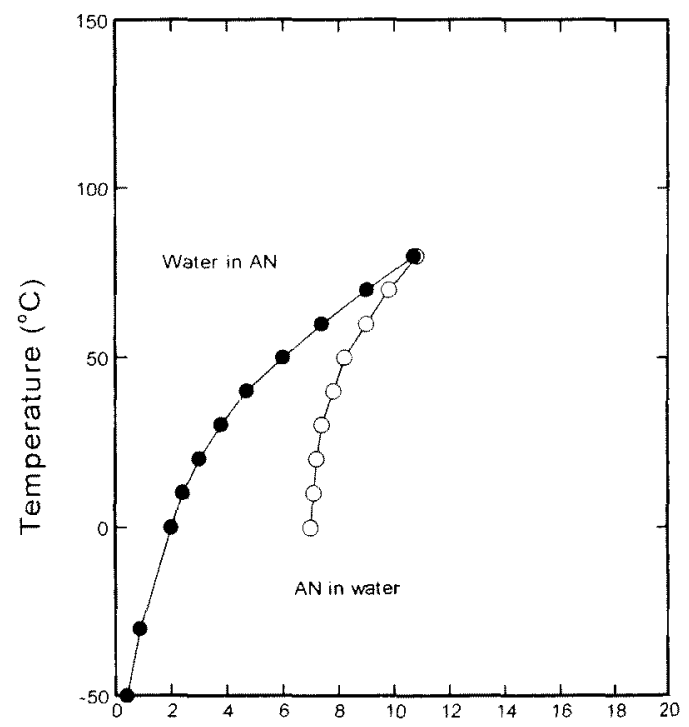

Water or AN content in mixture (weight \%)

Fig. 3 Solubilities of acrylonitrile and water.

$2.5 \%$ と Nの場合と近いためと考之られる。

これらの結果およU゙前報で示したPAN/AN/水の溶融 举動より $\mathrm{AN} /$ 水の相溶温度以上ではPAN/AN/水 3 元系 は溶融状態になると判断できる。

\section{2 重合}

\section{2 .1 重合開始凨}

溶融状態での重合は鼬度が亶く重合開始剤の分解(ラジ 
カル生成) 速度が速くなると予想されるため, 水系重合で 広く便用されているレドックス開始骫は使用せず，有機 過酸化物であるパーブチルD(Di-tert-butyl peroxide) およびBPO(Benzoyl peroxide), とアゾ系化合物AIBN (2,2'azobisisobutyronitrile) 重合開始骫として用いた。

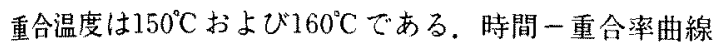
をFig.4に示した。パーブチルDを開始㘊とした場合には 㥛めて急激に重合反応が進み，約10分間で重合率は90\% 程度に達した、パーブチルDを使用した場合には、ガラス 封管の䄪半数が反応中に破損し，急激な反応熱のため系 内温度が設定温度より高くなり，暴走反応的に重合が進 んだものと推測される。一方，BPOおよびAIBNを開始 削とした場合には比較的踬やかに重合率は上异し，30分 間で約 $80 \% ， 60$ 分間で約 $90 \%$ に達した。重合開始剂の活 性化エネルギーおよび10時間半減温度 (半減期が10時間と なる䀅度)は, AIBNで $3.13 \times 10^{4} \mathrm{cal} / \mathrm{mol}, 64^{\circ} \mathrm{C}$ ，パーブ チルDで $3.51 \times 10^{4} \mathrm{cal} / \mathrm{mol}, 124^{\circ} \mathrm{C}, \mathrm{BPOで} 3.11 \times 10^{4} \mathrm{cal} /$ $\mathrm{mol}, 74^{\circ} \mathrm{C}$ であり, $\mathrm{PAN} / \mathrm{AN} / \mathrm{H}_{2} \mathrm{O}$ 系が溶融状態となる150 $\mathrm{C}$ 以上の温度での重合反応を制御下に行うには10時間半減 温度が約 $80^{\circ} \mathrm{C}$ 以下の開始郕を使用するのが望ましいと考 六林。

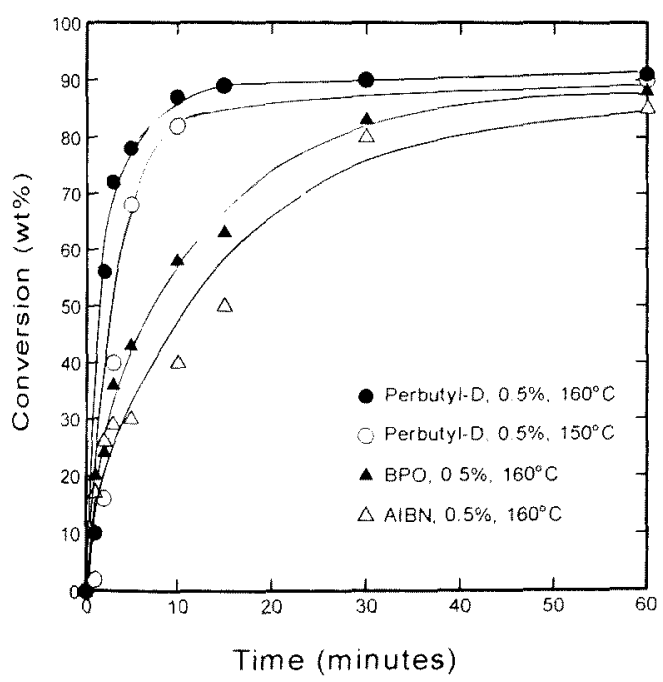

Fig. 4 Time-conversion curves of AN/MA copolymerization.

\subsection{2 重合体組成}

ANとMA，MMAおよびVAcの単量体仕込み組成と得 られた重合体のAN組成をTable 1に示した。この值を用 いてFinemann-Ross法で求めた反応性比 $\left(\mathrm{r}_{1}, \mathrm{r}_{2}\right)$ をTable に示した.AN/MA系拉よU゙AN/VAc柔では溶融重合で の反応性の值はバルク重合で得られた值に比較して, 反
応性比の積 $\left(\mathrm{r}_{1} \cdot \mathrm{r}_{2}\right)$ は小さくなった。すなわち,ブロック 性が低下して交互性が高くなっている。水溶性重合開始 堉を用いな水系影濁重合の場合と比較すると $\left(\mathrm{r}_{1} \cdot \mathrm{r}_{2}\right)$ は AN/ MA系, AN/MMA系共に同等あるいはやや小さい値とな っている，バルク重合，水系苼濁重合いずれの場合も生 成した重合体はモ/マー，水に対して不溶であり不均一 相となるのに対し，溶融重合では生成した重合体も含め 均一相になっていることが交互性を高めたものと考えら れる。

得られた反応性比から求めた共重合曲線をFig.5 6, 6 示した、いずれのモ/マー系でもバルク重合, 水系䋰濁 重合の場合よりもポリマー組成は仕这みモノマー組成に

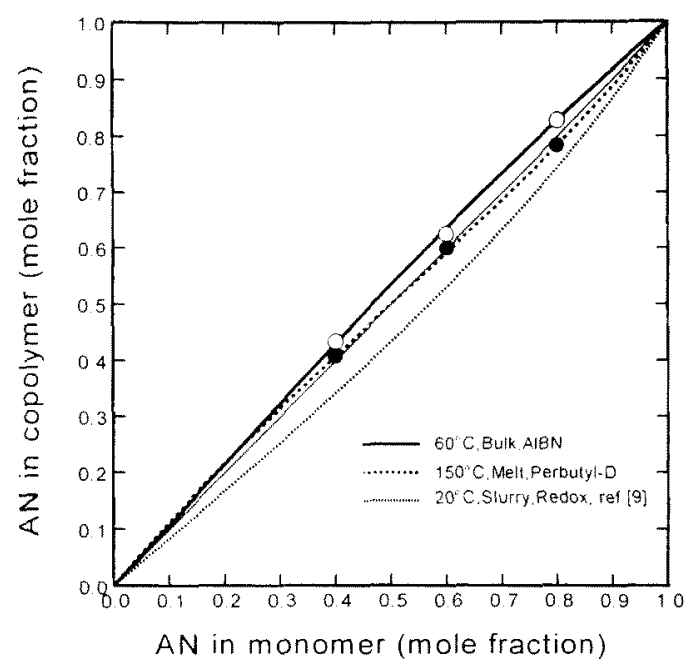

Fig. 5 Copolymerization curves of AN/MA.

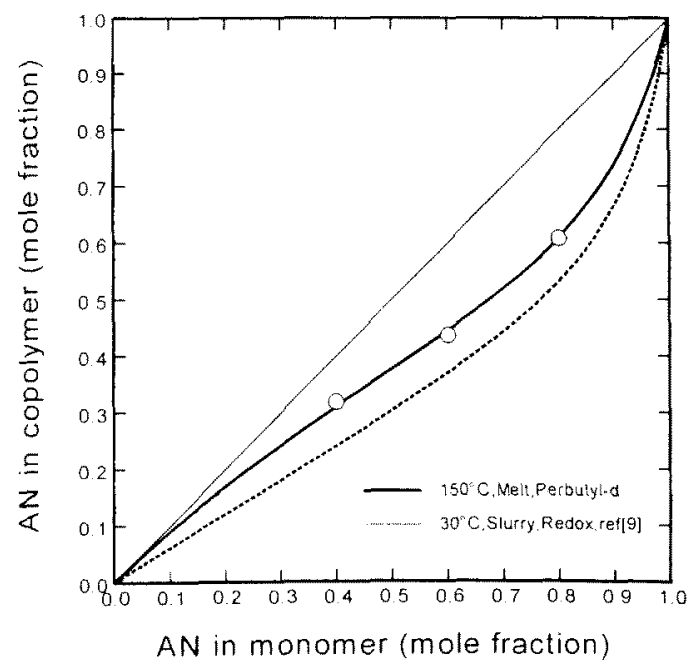

Fig. 6 Copolymerization curves of AN/MMA. 
Table 1 Relationship between monomer and polymer composition

\begin{tabular}{ccccccc}
\hline No. & Initiator & Comonomer & $\begin{array}{c}\text { Temperature } \\
\left({ }^{\circ} \mathrm{C}\right)\end{array}$ & $\begin{array}{c}\text { AN in monomer } \\
(\mathrm{mol} \%)\end{array}$ & $\begin{array}{c}\text { Conversion } \\
(\%)\end{array}$ & $\begin{array}{c}\text { AN in polymer } \\
(\mathrm{mol} \%)\end{array}$ \\
\hline 2 & AIBN*1 & MA & 60 & 80.0 & 4.0 & 82.8 \\
3 & $"$ & MA & 60 & 60.0 & 6.0 & 62.6 \\
4 & $"$ & MA & 60 & 40.0 & 3.2 & 43.4 \\
\hline 7 & Perbutyl-D*2 & MA & 150 & 80.0 & 3.6 & 78.4 \\
8 & $"$ & MA & 150 & 60.0 & 2.5 & 60.0 \\
9 & $"$ & MA & 150 & 40.0 & 2.4 & 40.8 \\
\hline 13 & $"$ & MMA & 150 & 80.0 & 7.3 & 60.7 \\
14 & $"$ & MMA & 150 & 60.0 & 7.9 & 43.5 \\
15 & $"$ & MMA & 150 & 40.0 & 6.3 & 31.8 \\
\hline 18 & $"$ & VAc & 150 & 80.0 & 3.7 & 90.2 \\
20 & $"$ & VAc & 150 & 60.0 & 7.4 & 71.5 \\
21 & $"$ & VAc & 150 & 40.0 & 6.8 & 57.4 \\
\hline
\end{tabular}

*12-Azo-bis-2-isobutyronitrile ${ }^{* 2}$ Di-tert-buthyl peroxide

Table 2 Reactivity ratio of AN copolymerization with MA, MMA, and VAc

\begin{tabular}{|c|c|c|c|c|c|c|c|c|}
\hline$M_{1}$ & $\mathrm{M}_{2}$ & $\mathrm{r}_{1}$ & $\mathrm{r}_{2}$ & $\begin{array}{l}\text { Polymerization } \\
\text { Initiator }\end{array}$ & $\begin{array}{l}\text { condition } \\
\text { Temperature }\end{array}$ & $r_{1} \cdot r_{2}$ & Note & ref. \\
\hline AN & $\mathrm{MA}$ & 1.24 & 0.95 & AIBN & $60^{\circ} \mathrm{C}$ & 1.18 & Bulk & \\
\hline$A N$ & $\mathrm{MA}$ & 0.85 & 0.85 & Perbutyl-D & $150^{\circ} \mathrm{C}$ & 0.72 & Melt & \\
\hline $\mathrm{AN}$ & MA & 1.4 & 0.95 & AIBN & $60^{\circ} \mathrm{C}$ & 1.33 & Bulk & [5] \\
\hline $\mathrm{AN}$ & $\mathrm{MA}$ & 1.5 & 0.84 & $\mathrm{BPO}^{* 1}$ & $60^{\circ} \mathrm{C}$ & 1.26 & in Benzene & [8] \\
\hline $\mathrm{AN}$ & MA & 0.7 & 1.22 & $\mathrm{APS}^{* 2} / \mathrm{NaHSO}_{3}$ & $20^{\circ} \mathrm{C}$ & 0.85 & Slurry & [9] \\
\hline $\mathrm{AN}$ & MMA & 0.24 & 1.06 & Perbutyl-D & $150^{\circ} \mathrm{C}$ & 0.25 & Melt & \\
\hline $\mathrm{AN}$ & MMA & 0.15 & 1.65 & $\mathrm{APS} / \mathrm{NaHSO}_{3}$ & $30^{\circ} \mathrm{C}$ & 0.25 & Slurry & [9] \\
\hline$\overline{A N}$ & VAc & 2.10 & 0.04 & Perbutyl-D & $150^{\circ} \mathrm{C}$ & 0.08 & Melt & \\
\hline $\mathrm{AN}$ & VAc & 6.0 & 0.07 & $\mathrm{BPO}$ & $70^{\circ} \mathrm{C}$ & 0.42 & Bulk & [6] \\
\hline AN & VAc & 6.0 & 0.02 & $\mathrm{BPO}$ & $60^{\circ} \mathrm{C}$ & 0.12 & Bulk & [7] \\
\hline
\end{tabular}

${ }^{* 1}$ Benzoyl peroxide ${ }^{* 2}$ Ammonium persulfate

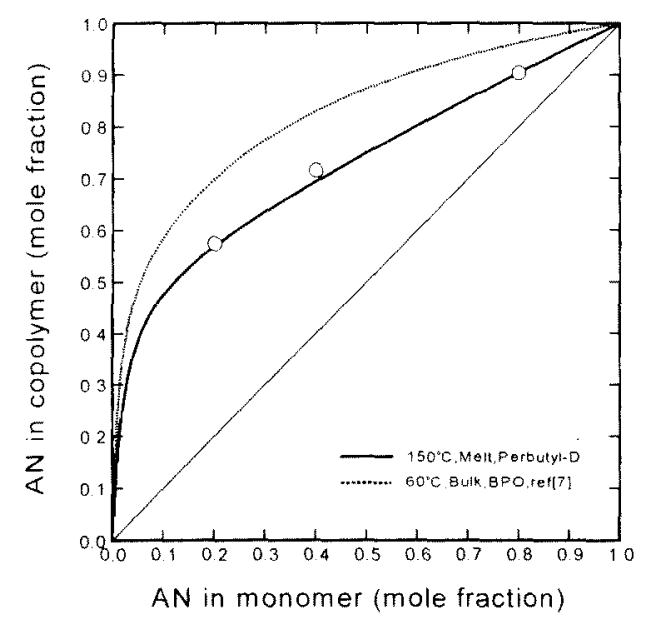

Fig. 7 Copolymerization curves of AN/VAc.
より近い組成となった，以上のことから，溶融重合によ る重合体は跑濁重合, バルク重合のような不均一系での 重合による重合体よりも均一な組成分布を持つものと推 测できる。

\section{2 .3 着色防止剂}

溶融重合で得られたポリマーのDMF溶液のAPHAカラ 一を測定すると615であり，水系䝮濁重合によるポリマー の約50に比較して著しく着色している。これは重合時の 熱着色によるものと考之られる。この着色を改良するた め各種の着色防止㑉を重合系に添加して, 重合を行った 結果をTable 3に示した，一般に着色防止剂はラジカル捕 捉により酸化を防止するものであり、これらを重合系に 添加した場合には重合率の低下や分子量の低下を生しる 恐れがある。したがって，着色防止剤の使用においては 
Table 3 Polymerization Results with Anti-coloring Reagents

\begin{tabular}{|c|c|c|c|}
\hline Anti-coloring Reagents & $\%$ Conversion & $\mathrm{Mw}\left(\times 10^{4}\right)$ & APHA Index \\
\hline Control (No Reagent) & 88.6 & 7.46 & 615 \\
\hline 2,6-ditert-butyl-4-methyl phenol & 83.6 & 9.24 & 495 \\
\hline 4,'-buthylidene bis (6-tert-butyl-3-methyl) phenol & 83.3 & 9.24 & 420 \\
\hline $2,2^{2}$-methylene bia (6-tert-butyl-4-methyl) phenol & 81.5 & 5.34 & 545 \\
\hline Alkylated bisphenol & 84.6 & 5.26 & 495 \\
\hline 1,1'bis (4-hydroxyphenyl) cyclohexane & 84.1 & 7.36 & 710 \\
\hline Styrenated phenol & 85.6 & 7.27 & 470 \\
\hline Triphenyl phosphite & 89.3 & 5.18 & 480 \\
\hline Tris nonyl phenyl phosphite & 82.8 & 5.09 & 530 \\
\hline Di-lauryl 3,3'-thiodipropionate & 92.9 & 9.34 & 470 \\
\hline Di-stearyl 3,3 'thiodipropionate & 90.4 & 9.24 & 590 \\
\hline 4,4-thiobis (6-tert-butyl-3-methyl) phenol & 56.9 & - & 380 \\
\hline mono-ethanolamine & 86.5 & - & 800 \\
\hline Tri-ethanolamine & 88.1 & - & 825 \\
\hline Tri-ethylamine & 85.1 & - & 1,010 \\
\hline Ethylene-diamine & 81.4 & - & 780 \\
\hline Di-phenylamine & 84.0 & 9.75 & 680 \\
\hline 1,3-diphenyl urea & 95.8 & 10.49 & 690 \\
\hline Zinc Dimethyl-dithiocarbamine & 87.8 & 3.84 & 1,120 \\
\hline Benz-imidasole & 95.1 & 6.70 & 675 \\
\hline Sodium metasulfite & 88.4 & 7.36 & 520 \\
\hline$\beta$-Naphtol & 83.3 & 7.56 & 750 \\
\hline Dibenzyl disulfide & 89.5 & 12.43 & 445 \\
\hline$\beta$-mercapto propionic acid & 76.3 & 3.84 & 495 \\
\hline Tert-lauryl mercaptane & 81.9 & 6.15 & 490 \\
\hline 2-Mercapto ethanol & 88.5 & 6.80 & 520 \\
\hline
\end{tabular}

Note 1) Polymerization Monomer: $\mathrm{AN} / \mathrm{MA}=90 / 10 \mathrm{wt} \%$. Monomer Concentration $=80 \%$, Initiator: perbutyl-0, $0.5 \%$ to monomer Temperature $\times$ time $=150^{\circ} \mathrm{C} \times 60$ minutes, anti-coloring reagent $=2 \%$ to monomer

2) APHA color Polymer $/ \mathrm{DMF}=0.4 \mathrm{~g} / 20 \mathrm{ml}, 5 \mathrm{~cm}$ cell at $420 \mathrm{~nm}$

重合率, 分子量人の影響を考虐して選択する必要がある. Table 3の実験結果でも，例之ば, 4,4'-thiobis(6-tert-butyl3-methyl) phenolは最も低いAPHAカラーを示したにもか か⿰力口゙す，著しい重合率の低下を引き起こし実用的な重 合变が得られていない，重合率，分子量とカラーのバラ ンスが見て4,4'-butylidene bis (6-tert-butyl-4-methyl) phenolfよびDibenzyl disulfideが比較的良好な結果を与 えたが、現在アクリル繊維の原料として使用されている 水系㮣濁重合によるポリマーに相当するレヘルには至ら なかった。

\section{4. 結 論}

前報で報告した流動性を示すPAN/水/ANの 3 元系を 重合組成と重合率の制御で得られることを溶融重合によ
り確認した。この時に用いる重合開始剂は10時間半減温 度が約 $80^{\circ} \mathrm{C}$ 以下であることが望ましいこと, 織維化した とき一般的織維物性在得られる分子量の重合体が得られ ること、また，得られた重合体は水柔態濁重合やバルク 重合などの不均一系重合で得られるポリマーに比へ，交 互性が高く，仕这及組成により近い租成となることを示 した，更に，ポリマーの着色に対する各種着色防止剤の 効果についても検討したが，水系瑟濁重合ポリマーと同 等レベルには達しなかっった。

これらのことから，溶融重合を連続化し，生成した重 合体を紡系することが可能であると考之られる。工業的 規模でのPANの溶融紡系においては，上記したポリマー の着色を防止することが大きな課題となることが予想さ れる。 
本研究の一部は，日本維維機械学会北陸支部研究発表 会(平成 8 年12月，高阙)で発表した。

\section{文献}

1. 塩田, 松平, 馀維学全誌, 53，62-66(1997)。

2. "Acrylonitrile safe storage and handling guide", (1994), BP America Inc.

3. T. Shibukawa, M. Sone, A. Uchida, K. Iwabori, J. Polymer Sci., 6, 147 (1968).

4. 高分子学全編, 「其重合 1 」, 培風館, p.60(1975).
5. T. Tomikado, Y. Iwakura, J. Polymer Sci., 36, 529532 (1959).

6. T. Alfrey, J. Bohrer, H. Haas, C. Lewis J. Polymer Sci., 5, 719-726(1950).

7. R. Fordyce, E. Chapin, G. Ham J. Am. Chem. Soc., 70, 2489-2492 (1948).

8. C. Marvel, R.Schen J. Am. Chem. Soc., 70,6003-6005 (1957).

9. 柚口貞夫, 渡辺正元, 高分子化学, 15, 129-135(1958). 